\title{
Review
}

\section{Calcium and Mitochondrial Reactive Oxygen Species Generation: How to Read the Facts}

\author{
Vera Adam-Vizi ${ }^{\mathrm{a}, *}$ and Anatoly A. Starkov ${ }^{\mathrm{b}}$ \\ ${ }^{a}$ Department of Medical Biochemistry, Semmelweis University, Neurobiochemical Group of Hungarian Academy of \\ Sciences, Budapest, Hungary \\ ${ }^{\mathrm{b}}$ Weill Medical College Cornell University, New York, NY, USA
}

Accepted 29 March 2010

\begin{abstract}
A number of recent discoveries indicate that abnormal $\mathrm{Ca}^{2+}$ signaling, oxidative stress, and mitochondrial dysfunction are involved in the neuronal damage in Alzheimer's disease. However, the literature on the interactions between these factors is controversial especially in the interpretation of the cause-effect relationship between mitochondrial damage induced by $\mathrm{Ca}^{2+}$ overload and the production of reactive oxygen species (ROS). In this review, we survey the experimental observations on the $\mathrm{Ca}^{2+}$-induced mitochondrial ROS production, explain the sources of controversy in interpreting these results, and discuss the different molecular mechanisms underlying the effect of $\mathrm{Ca}^{2+}$ on the ROS emission by brain mitochondria.
\end{abstract}

Keywords: Calcium, mitochondria, permeability transition, reactive oxygen species

\section{INTRODUCTION}

Mitochondrial dysfunction has been recognized to play an important role in the pathogenesis of neurodegenerative disease. In the case of Alzheimer's disease (AD), oxidative stress together with mitochondrial dysfunction appear at the early stage of the pathology [14] (for review, see [5]), but the underlying mechanism is unknown. Abnormal metabolism of reactive oxygen species (ROS) as an aggravating or primary factor in numerous pathologies, neurodegenerative diseases including AD, and senescence is firmly established, widely recognized, and extensively reviewed elsewhere [6$14]$.

${ }^{*}$ Correspondence to: Vera Adam-Vizi MD, PhD, Department of Medical Biochemistry, Semmelweis University, Budapest H-1094 Tuzolto st. 37-47, Hungary. Tel.: +361 266 2773; Fax: +361 267 0031; E-mail: veronika.adam@eok.sote.hu.
Oxidative damage is readily detected in $\mathrm{AD}$ postmortem tissue [15]; it is the earliest event [3] that could be detected in the brain prior to amyloid- $\beta(\mathrm{A} \beta)$ plaque formation [3] and onset of symptoms of $\operatorname{AD}[3,16,17]$. Oxidative damage to lipids also occurs before $\mathrm{A} \beta$ deposition in $\mathrm{AD}$ transgenic mice [18]. The $\mathrm{A} \beta$ deposits in transgenic mouse models are associated with evidence of oxidative stress as assessed by elevated expression of $\mathrm{Cu} / \mathrm{Zn}$ superoxide dismutase and heme oxygenase-1, and increased markers of lipid peroxidation [19-21]. It has also been reported that fibrillar deposits of $\mathrm{A} \beta$ protein are associated with oxidative damage [22] and $\mathrm{A} \beta$ binding alcohol dehydrogenase (ABAD) has been suggested as a molecular mechanism of $\mathrm{A} \beta$ mitochondrial toxicity [23]. Oxidative damage may elevate $\mathrm{A} \beta_{1-42}$ levels by stimulating $\beta$-secretase [24]. For the pathology of sporadic $\mathrm{AD}$, a mitochondrial cascade concept was proposed suggesting that mitochondrial dysfunction is the primary event causing $\mathrm{A} \beta$ deposition [25]. Indications of oxidative damage in $\mathrm{AD}$ were found not 
only in brain regions but also in peripheral tissues [2629].

Considering that ROS-induced oxidative stress is a critical factor in injury and that mitochondria are most likely the major source of these ROS, it is clear that studies of ROS metabolism in AD brain mitochondria could provide critical knowledge needed for successful pharmacological intervention strategies to reduce neural cell death.

Elevated intracellular $\mathrm{Ca}^{2+}$ and abnormal $\mathrm{Ca}^{2+}$ signaling have long being recognized as marker features in AD which led to the formulation of the " $\mathrm{Ca}^{2+}$ hypothesis" of brain aging and AD by Khachaturian [30]. This hypothesis postulated that abnormal $\mathrm{Ca}^{2+}$ homeostasis mediates or directly causes most manifestations of $\mathrm{A} \beta$ peptide-induced neuronal damage in $\mathrm{AD}$. Recently, this idea has experienced a powerful boost by a string of findings $[31,32]$ (reviewed in $[33,34]$ ) that demonstrate the molecular mechanisms of $\mathrm{A} \beta$-mediated disruption of $\mathrm{Ca}^{2+}$ homeostasis. To date, a number of studies have amply documented various feedback loops linking mitochondrial dysfunctions, oxidative stress, amyloid$\beta$ protein precursor processing, $\mathrm{A} \beta$ toxic effects, and $\mathrm{Ca}^{2+}$ homeostasis in AD. It is beyond our scope to review all this literature here. Neither does it seem necessary as it has been extensively, comprehensively, and recently reviewed elsewhere (e.g., see [35-37]). Instead, we focus on an important aspect of this research field; the relation between mitochondrial ROS production and $\mathrm{Ca}^{2+}$ overload.

$\mathrm{Ca}^{2+}$ is a key element in physiological signal transductions and also equally important in pathological processes [38-40]. The primary beneficial role of $\mathrm{Ca}^{2+}$ in mitochondria by far is the promotion of ATP synthesis, which results from stimulation of the Krebs cycle enzymes and oxidative phosphorylation [41-43]. This effect is achieved by physiological $\mathrm{Ca}^{2+}$ signals and enables the adjustment of ATP production to cellular demand. The mechanisms of the harmful effect of $\mathrm{Ca}^{2+}$ on mitochondria is less well characterized, but is generally assumed to involve high $\mathrm{Ca}^{2+}$ loads and excessive ROS generation (for review, see [44,45]). However, data available from in vitro studies are very contradictory as to the effect of $\mathrm{Ca}^{2+}$ on mitochondrial ROS generation ranging from a significant decrease [46-48] to a substantial stimulation [49-52]. For the understanding of the pathology in neurodegenerative conditions, it is crucial to have a clear conception of the factors and conditions which determine the mitochondrial ROS generation in response to a $\mathrm{Ca}^{2+}$ challenge. In this review we discuss and summarize the possible mechanisms which could contribute to a $\mathrm{Ca}^{2+}$-dependent ROS generation in brain mitochondria.

\section{BRIEF OVERVIEW OF MITOCHONDRIAL ROS GENERATING AND ELIMINATING SYSTEMS}

Several decades of research have firmly established that ROS production is inherent to mitochondrial oxidative metabolism and revealed numerous sources of ROS in mitochondria (Fig. 1). This literature has been extensively reviewed by us and others elsewhere (e.g., [13, 53-63]).

Mitochondria oxidize various substrates generated inside and outside mitochondria. In the brain, the Krebs cycle mainly generates NADH and $\mathrm{FADH}_{2}$, which in turn are oxidized in reactions catalyzed by several enzyme complexes located in the inner membrane of mitochondria. The flux of electrons from substrates through various redox carriers and centers in these enzymes is ultimately terminated in a 4-electron reduction of molecular oxygen to water, catalyzed by cytochrome c oxidase. However, some proportion of electrons is diverted from the flow and participates in a singleelectron reduction of oxygen, thereby converting it into superoxide, a primary ROS, which quickly dismutates to form $\mathrm{H}_{2} \mathrm{O}_{2}$. The latter is membrane permeable and diffuses out of mitochondria. The highest ROS producing capacity in brain mitochondria has been demonstrated for complex I and complex III of the respiratory chain [64-67] and the enzyme dihydrolipoamide dehydrogenase [68-70]. In intact mitochondria, the activities of various ROS sources are linked to each other through the common pools of intermediates such as NADH and CoQ, thus it is not possible to determine under physiological conditions, when the complexes are not inhibited, which one of the possible sites is the major ROS generator. Vast amount of studies have documented that inhibitors of complex I and complex III induce robust ROS release from isolated brain mitochondria [71-75]. However, only complex I inhibition appears to be physiologically important in light of the observation made on in situ synaptic mitochondria, that $\sim 16 \%$ inhibition of complex I is already accompanied by an enhanced ROS formation, whereas complex III needs to be inhibited by $>70 \%$ for an increase in ROS generation [76]. This amount of complex III inhibition is unlikely to be an underlying in vivo mechanism of pathological ROS generation.

ROS production capacity of mitochondria is controlled by factors affecting and reflecting the metabolic state of intact mitochondria. It has been found that the chemical nature of the substrates fuelling the respiratory chain, the amplitude of the membrane poten- 


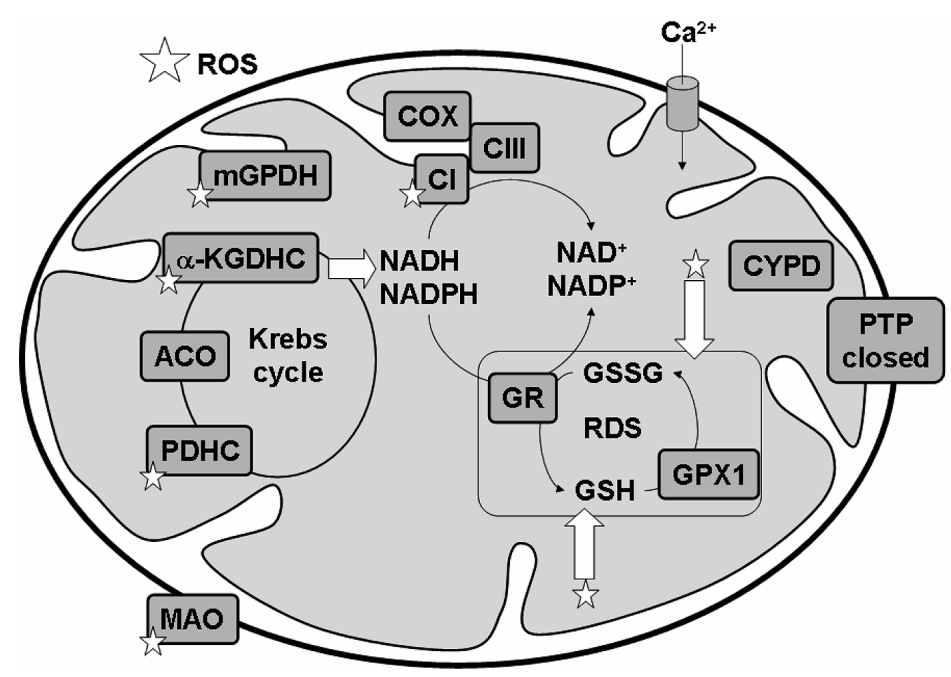

Fig. 1. Mitochondrial ROS production and scavenging. Abbreviations: mGPDH, mitochondrial alpha-glycerophosphate dehydrogenase located at the outer surface of inner mitochondrial membrane which is pictured as a solid line; C1, CIII, COX, respiratory chain complexe I and III, and cytochrome oxidase, respectively; $\alpha$-KGDHC, alpha-ketoglutarate dehydrogenase complex; ACO, aconitase, PDHC, pyruvate dehydrogenase complex; MAO, monoamine oxidases located in the outer membrane of mitochondria; GR, glutathione reductase; GPX1, glutathione perodixase I, RDS, other enzymes of mitochondrial ROS defense system including (not pictured) manganese SOD, peroxiredoxins 3 and 5, glutaredoxin 2, thioredoxin 2 and thioredoxin reductase, glutathione S-transferase, catalase, $\mathrm{Cu}, \mathrm{Zn}$ superoxide dismutase, and phospholipid hydroperoxide glutathione peroxidase 4 (see [68] for a review); GSH and GSSG, reduced and oxidized glutathione; CYPD, cyclophilin D. PTP, mitochondrial permeability transition pore. Stars indicate reactive oxygen species (ROS); enzymes labeled with stars are ROS sources.

tial in mitochondria $(\Delta \Psi \mathrm{m})$, the $\mathrm{pH}$ of the matrix, and the oxygen tension in their surrounding $[55,68]$ are the most important factors controlling the ROS production in mitochondria. Out of these, the importance of substrates and $\Delta \Psi \mathrm{m}$ are discussed below in association with the effect of $\mathrm{Ca}^{2+}$ on ROS generation.

The 'ROS defense system' (RDS) comprises several enzymes specialized for removal of superoxide, $\mathrm{H}_{2} \mathrm{O}_{2}$, and organic hydroperoxides. Most of these enzymes are ubiquitously present in all mammalian mitochondria; the expression level of these enzymes exhibits tissue and species specificity. A unique feature of RDS is that almost all of its enzymes rely on NADPH as a source of reducing equivalents needed for their activity. The NADPH reduction is carried out by three intramitochondrial enzymes; isocitrate dehydrogenase (NADPH linked), malic enzyme, and transhydrogenase [77]. To note, the intramitochondrial pools of NADPH and reduced glutathione (GSH) are rather large (ca. 3-5 mM NADPH [78,79] and 2-14 mM GSH [80-83]), therefore, transient changes in the activity of enzymes would not immediately affect the RDS and its ability to extinguish short bursts in ROS concentration. However, a prolonged activity of RDS, its 'endurance', ultimately depends on the supply of NADPH and GSH, thus depending on the ability of enzymes to regenerate these compounds.
It is clear that elevated mitochondrial ROS emission may be determined by both a true increase in ROS generation from a mitochondrial site and a failure of mitochondrial RDS. However, for the purpose of designing an intervention to prevent oxidative stress and tissue damage by mitochondrial ROS, in-depth knowledge of the mechanism of ROS emission is crucial. To the best of our knowledge, this issue has not yet been addressed in details for AD brain mitochondria.

\section{VARIABLE EFFECTS OF Ca ${ }^{2+}$ ON MITOCHONDRIAL ROS GENERATION}

In general, an effect of $\mathrm{Ca}^{2+}$ on mitochondrial ROS formation requires the influx of $\mathrm{Ca}^{2+}$ into the matrix. In brain mitochondria, the primary mechanism of $\mathrm{Ca}^{2+}$ uptake is via a highly selective ion channel, termed uniporter, driven by the electrochemical gradient across the mitochondrial inner membrane. This channel exhibits remarkable low affinity for $\mathrm{Ca}^{2+}$ [84]. While the kinetic and pharmacological nature of this channel is well-characterized, the molecular entity of the channel remains to be identified. The electrophoretic $\mathrm{Ca}^{2+}$ entry involves a net charge movement, therefore lowering $\Delta \Psi \mathrm{m}$. For liver and heart mitochondria, an additional "rapid mode" uptake has been described [85, 
86] allowing fast changes in matrix $\mathrm{Ca}^{2+}$ concentration and rapid stimulation of $\mathrm{Ca}^{2+}$-dependent processes. In cardiac mitochondria, a ryanodine receptor has been identified, which might also mediate $\mathrm{Ca}^{2+}$ entry into the matrix [87].

Rapid efflux of $\mathrm{Ca}^{2+}$ from the matrix requires $\mathrm{Na}^{+} / \mathrm{Ca}^{2+}$ exchange coupled to $\mathrm{H}^{+} / \mathrm{Na}^{+}$exchange via the inner membrane of mitochondria (see [88]). A possible efflux pathway for $\mathrm{Ca}^{2+}$ is the mitochondrial permeability transition pore (PTP), which is a large conductance channel formed by proteins in the inner and outer membrane of mitochondria allowing the release of solutes $<1.5 \mathrm{kDa}$ including GSH and pyridine nucleotides from the matrix and leading to loss of $\Delta \Psi \mathrm{m}$, osmotic swelling, and rupture of the outer mitochondrial membrane [89-92].

There is a general conception that $\mathrm{Ca}^{2+}$ overload leads to stimulated ROS generation in mitochondria. However, data are available in the literature both demonstrating this and indicating the opposite. Mitochondrial $\mathrm{Ca}^{2+}$ accumulation has been shown to promote [50,51,93,94], to be without an effect on [95-97], or to decrease ROS generation [46-48]. These studies, even only those performed with brain mitochondria, are difficult to compare due to the great variance in the conditions at which the $\mathrm{Ca}^{2+}$ challenge is imposed and mitochondrial ROS generation is measured. In order to understand the mechanism by which $\mathrm{Ca}^{2+}$ stimulates or decreases ROS generation, it is crucial to consider key factors which possibly determine the response of mitochondria to a $\mathrm{Ca}^{2+}$ challenge. Since isolated mitochondria are used in the vast majority of these studies, the choice of the substrate(s) fuelling the respiratory chain is an obvious variable; whether electrons are donated to complex I or to coenzyme Q (CoQ). An important factor is the metabolic state of mitochondria before and under the $\mathrm{Ca}^{2+}$-load which determines whether $\mathrm{Ca}^{2+}$-induced changes in ROS generation would be dependent on $\Delta \Psi \mathrm{m}$. A sharp distinction is made by the fact whether mitochondria undergo $\mathrm{Ca}^{2+}$-dependent PTP opening or could handle the $\mathrm{Ca}^{2+}$-load without a major inner membrane permeability increase. These conditions should be carefully scrutinized for the interpretation of the effect of $\mathrm{Ca}^{2+}$ on mitochondrial ROS emission.

\section{SUBSTRATE-DEPENDENCE OF THE EFFECT OF $\mathrm{Ca}^{2+}$ ON ROS GENERATION}

Mitochondrial respiration in vitro can be supported either by substrates linked to $\mathrm{NAD}^{+}$reduc- tion (glutamate, malate, $\alpha$-ketoglutarate, pyruvate) donating the electrons to FMN cofactor of complex I, or by FAD-linked substrates (succinate, $\alpha$ glycerophosphate), which reduce the more distal CoQ pool in the respiratory chain. In the case of $\mathrm{NAD}^{+}$. linked substrates, complex I generates superoxide with electrons from the fully reduced FMN $[60,98]$. The reduction state of FMN is set by the NADH/NAD ${ }^{+}$ratio, therefore anything that increases this ratio, either inhibition of the respiratory chain or a low ATP demand, will increase ROS generation $[60,99,100]$.

In the presence of FAD-reducing substrates and when $\Delta \Psi \mathrm{m}$ is high, electrons can flow back to complex I (reverse electron transport; RET) and reduce $\mathrm{NAD}^{+}$to NADH [101,102]. Superoxide is generated with high rate under this condition $[71,99,103]$, possibly at the same site; the FMN coenzyme of complex I [60]. RET is favored in mitochondria supported by $\mathrm{FADH}_{2}$-dependent substrates, such as succinate or $\alpha$ glycerophosphate but only when ubiquinone is highly reduced at a high $\Delta \Psi \mathrm{m}$. This is typically a condition easily created in vitro with isolated mitochondria, but in vivo the dominance of electron input from $\mathrm{NAD}^{+}$linked substrates makes this process unlikely, though not impossible. It has been postulated [13] that during hypoxia succinate concentration could rise to a sufficiently high level to generate high $\Delta \Psi \mathrm{m}$ and ROS generation at complex I during reoxygenation. Supportive for this is the finding [104] that succinate stimulates ROS formation even in the presence of $\mathrm{NAD}^{+}$-linked substrates without preventing their oxidation. It has been shown that 5 min of ischemia decreased the concentrations of glycolytic intermediates and mitochondrial NAD-linked oxidative substrates, but increased succinate concentration by $\sim 300 \%$ to the millimolar range in rat brain $[105,106]$. Another interesting finding is that hypoxia significantly ( $>60 \%$ ) activated succinate and glutamate oxidation by isolated rat brain mitochondria [107,108].

However, since RET is highly sensitive to $\Delta \Psi \mathrm{m}$ and a small decrease in $\Delta \Psi \mathrm{m}$ inhibits succinate-dependent ROS generation [109], it is unlikely that $\mathrm{Ca}^{2+}$ uptake, which decreases $\Delta \Psi \mathrm{m}$, could stimulate ROS generation via RET. On the contrary, ROS release from succinate-supported brain mitochondria is immediately and almost completely inhibited by a $\mathrm{Ca}^{2+}$ overload [48]. Similarly, ROS release from well-coupled brain mitochondria respiring on $\alpha$-glycerophosphate is reduced by high $\mathrm{Ca}^{2+}$ loads (L. Tretter, unpublished observation) consistent with the $\Delta \Psi$ m-dependent character of the RET-related ROS generation in these [110] 
and other mitochondria [111]. It is of note that $\mathrm{Ca}^{2+}$-induced decrease in RET-related ROS generation, which is due to a drop in $\Delta \Psi \mathrm{m}$, is observed only when conditions are unfavorable for PTP opening (in the presence of ADP or ATP or other PTP inhibitors). Without that, $\mathrm{Ca}^{2+}$-induced PTP dominates the response of mitochondria and determines the changes in ROS generation.

It has to be noted here that submicromolar concentrations of $\mathrm{Ca}^{2+}$ stimulate ROS production by mitochondrial $\alpha$-glycerophosphate dehydrogenase [112] likely due to stimulation of the enzyme described earlier in liver mitochondria [113], which might be significant in vivo in deenergized mitochondria, which are unable to take up $\mathrm{Ca}^{2+}$ and to control the cytosolic $\mathrm{Ca}^{2+}$ concentration.

In mitochondria supported by $\mathrm{NAD}^{+}$-linked substrates in vitro or respiring on endogenous substrates in vivo, $\mathrm{NADH} / \mathrm{NAD}^{+}$ratio is critical for ROS generation not only by complex I but also by the Krebs cycle enzyme, $\alpha$-KGDHC. A common feature of neurodegeneration in various diseases is a decline in the activity of mitochondrial enzymes, of which reduction in $\alpha$-KGDHC activity in AD is well documented [114-116] (for review see [117]). $\mathrm{A} \beta$, which is deposited in the mitochondria of AD patients and transgenic mice before substantial accumulation extracellularly $[23,118]$, has been shown in isolated brain mitochondria to inhibit $\alpha$-KGDHC [119]. $\alpha$-KGDHC is a key enzyme in the Krebs cycle providing NADH for complex I in the respiratory chain. This enzyme is sensitive to inhibition by different ROS including $\mathrm{H}_{2} \mathrm{O}_{2}$ [120-122], peroxynitrite [123], or intrinsic radical species [124]. More intriguing with relation to ROS generation is the ability of $\alpha$-KGDHC to generate ROS during its normal catalytic function attributable to the dihydrolipoamide dehydrogenase component of the enzyme [69,70,125] (for review, see [126]). The latter enzyme is the common component of pyruvate, $\alpha$-KGDHC, and branched-chain ketoacid dehydrogenase complexes, and also participates in glycine cleavage system [127]. ROS generation by $\alpha$-KGDHC is regulated by the $\mathrm{NADH} / \mathrm{NAD}^{+}$ratio; an increase in this ratio, while inhibiting the physiological catalytic activity, promotes ROS generation by the enzyme [70]. $\mathrm{Ca}^{2+}$ is a well known regulator of $\alpha$-KGDHC by activating the enzyme in low $\mu \mathrm{M}$ concentrations $[42,128]$. It was demonstrated with isolated $\alpha$-KGDHC that parallel with the activation of the enzyme, $\alpha$-KGDHC produces higher amount of $\mathrm{H}_{2} \mathrm{O}_{2}$ in the presence of $\mathrm{Ca}^{2+}[70]$. It is not possible yet to unambiguously de- termine to what extent $\alpha$-KGDHC contributes to mitochondrial ROS production in situ, let alone in vivo, but some in vitro data allow the cautious assumption that it might be significant under certain physiological or pathological conditions. Isolated brain mitochondrial produce the highest amount of ROS when supplied with $\alpha$-ketoglutarate as compared to other substrates [69]. Recently it has been reported that specific inhibitors of $\alpha$-KGDHC administered together with glutamate in cultured neurons, inhibited the glutamate-induced ROS production by about $20 \%$ suggesting that $\alpha$-KGDHC might be a source of ROS under glutamate stimulation [129]; the latter is known to involve accumulation of $\mathrm{Ca}^{2+}$ in mitochondria, to enhance ROS generation, and to induce cell death [130-137] (for a recent review, see [39]).

Given the activation of this enzyme by $\mathrm{Ca}^{2+}[42$, 128], one might expect an enhanced ROS production by $\alpha$-KGDHC under high $\mathrm{Ca}^{2+}$ loads. However, stimulation of the enzyme is only observed with $\leqslant 20 \mu \mathrm{M}$ $\mathrm{Ca}^{2+}$ concentration $[42,128]$ and it was demonstrated with brain mitochondria that the effect of $\mathrm{Ca}^{2+}$ is biphasic, activating the enzyme in low $\mu \mathrm{M}$ concentration but inducing progressive inhibition in $\geqslant 100 \mu \mathrm{M}$ concentrations [138]. In agreement with this, we found a stimulated ROS generation by isolated $\alpha$-KGDHC only in $\mathrm{Ca}^{2+}$ concentrations up to $20 \mu \mathrm{M}$ [70]. On the other hand, when respiration and oxidative phosphorylation is inhibited by high $\mathrm{Ca}^{2+}$ (see below), the $\mathrm{NADH} / \mathrm{NAD}^{+}$ratio increases, favoring an accelerated ROS generation by the enzyme. Due to the common pyridine nucleotide pool, it is not possible to establish the relative contribution of complex I and that of $\alpha$ $\mathrm{KGDHC}$ to the increased mitochondrial ROS emission promoted by an increased NADH/NAD ${ }^{+}$ratio.

\section{DEPENDENCE ON $\triangle \Psi$ OF THE EFFECT OF $\mathrm{Ca}^{2+}$ ON ROS GENERATION}

Given the fact that under certain conditions mitochondrial ROS generation is dependent on $\Delta \Psi$, it has to be considered whether depolarization associated with $\mathrm{Ca}^{2+}$ uptake could be a factor in the effect of $\mathrm{Ca}^{2+}$ on ROS formation.

The first evidence for the $\Delta \Psi$-dependent nature of ROS generation is that in isolated succinate-supported heart mitochondria, uncouplers decreased the rate of ROS emission [109,139]. Importantly, this effect was evident only in a narrow $\Delta \Psi$ range and only in wellcoupled, highly polarized mitochondria, where de- 
crease in $\Delta \Psi$ by only $10 \mathrm{mV}$ resulted in $80 \%$ decrease in the rate of ROS generation [109]. The 'turbo' mode of isolated mitochondria exhibiting high $\Delta \Psi$ and high rate of ROS formation is achieved only when bovine serum albumine (BSA) is present during the isolation or incubation to eliminate the uncoupling effect of contaminating free fatty acids, succinate is used as a respiratory substrate, and the experiments are performed in the absence of ADP [140]. The high protonmotive force in these mitochondria drives the back flow of electrons via complex I and RET is responsible for the high rate of ROS generation characteristic for these mitochondria (see above). With a few $\mathrm{mV}$ decrease in $\Delta \Psi$, the protonmotive force is no longer sufficient to maintain RET explaining the decrease in the rate of ROS generation. The $\Delta \Psi$-dependence of ROS generation with $\mathrm{NAD}^{+}$-linked substrates is also evident in the -150 and $-180 \mathrm{mV} \Delta \Psi$ range $[48,141]$ though the depolarization-induced decrease in ROS generation is less dramatic [46,142].

$\mathrm{Ca}^{2+}$ load depolarizes mitochondria due to the electrophoretic $\mathrm{Ca}^{2+}$ uptake [38], which may be transient or sustained depending on the amount of the $\mathrm{Ca}^{2+}$ load [143]. The substantial decrease in ROS emission by $\mathrm{Ca}^{2+}$ from succinate-supported mitochondria [46, $48,95]$ is evidently due to the elimination of RET. Reduction in the ROS release by $\mathrm{Ca}^{2+}$ was also observed in mitochondria respiring on $\mathrm{NAD}^{+}$-linked substrates $[46,48,95,143]$. The mechanism by which depolarization reduces mitochondrial $\mathrm{H}_{2} \mathrm{O}_{2}$ formation probably involves the oxidation of redox centers, which mediate the generation of superoxide. Again, for this effect of $\mathrm{Ca}^{2+}$, incubation conditions of mitochondria have to be favorable for high $\Delta \Psi$ and unfavorable for PTP induction (for example, presence of ATP but not ADP alone, to inhibit PTP induction or presence of ADP plus oligomycin to prevent PTP and ATP synthesis). Under these conditions $\mathrm{Ca}^{2+}$ load that causes sustained depolarization of the highly polarized mitochondria will decrease ROS emission $[48,143]$.

An opposite effect of $\mathrm{Ca}^{2+}$, e.g., stimulation of ROS release that is unrelated to PTP induction, is observed in mitochondria studied in the presence of ADP. Under physiological conditions, ADP (and ATP) is continuously present in the mitochondrial matrix controlling the rate of respiration and ATP synthesis, so it is highly adequate to include adenine nucleotides in the incubation medium for isolated mitochondria. ADP, on one hand, is an inhibitor of PTP induction [144-147], and, on the other, stimulates respiration and ATP synthesis, therefore decreases $\Delta \Psi$ (state 3 ). In these mitochon- dria, $\Delta \Psi$ is below the range in which ROS generation is dependent on $\Delta \Psi$, therefore $\mathrm{Ca}^{2+}$-induced PTPindependent depolarization is no longer expected to decrease ROS formation. In this case, the response of mitochondria depends on the amount of $\mathrm{Ca}^{2+}$ load; high $\mathrm{Ca}^{2+}$ concentrations, in our case 100-300 $\mu \mathrm{M}$, cause sustained depolarization but no alteration in ROS release from mitochondria [143], clearly showing the lack of effect of high $\mathrm{Ca}^{2+}$ load per se on the mitochondrial ROS producing machinery. However, in lower, but still pathological concentrations $(10-100 \mu \mathrm{M}), \mathrm{Ca}^{2+}$ depolarizes mitochondria only transiently; thereafter $\Delta \Psi$ recovers to a higher (more negative) value than that before the $\mathrm{Ca}^{2+}$ challenge. This 'after-hyperpolarization' parallels a significant increase in the ROS release from mitochondria [143]. The mechanism of the relative hyperpolarization following depolarization by moderate $\mathrm{Ca}^{2+}$ load is yet to be clarified but could be related to inhibition of the adenylate translocase [148] or $\mathrm{F}_{0} \mathrm{~F}_{1^{-}}$ ATPase by $\mathrm{Ca}^{2+}[149,150]$. Nonetheless, the stimulated ROS generation under this condition is most likely due to a shift of $\Delta \Psi$ towards higher values, into the range where ROS generation is sensitive to changes in $\Delta \Psi$. This phenomenon highlights another important variable that determines the changes of ROS emission from mitochondria in response to $\mathrm{Ca}^{2+}$ challenge; the amount of $\mathrm{Ca}^{2+}$ load.

In summary, in mitochondria actively synthesizing ATP (in the presence of ADP), therefore being depolarized, the effect of $\mathrm{Ca}^{2+}$ is dependent on the amount of $\mathrm{Ca}^{2+}$ load. In the lower range of $\mathrm{Ca}^{2+}$ load, transient $\mathrm{Ca}^{2+}$-induced depolarization is followed by a recovery to a relative hyperpolarized state and, due to the latter, ROS generation is stimulated, whereas large $\mathrm{Ca}^{2+}$ concentrations dissipate $\Delta \Psi$ without the tendency of recovery and fail to influence ROS emission from mitochondria. In highly polarized mitochondria not synthesizing ATP (in the presence of ATP and/or oligomycin) but exhibiting high rate of basal ROS generation, the drop in $\Delta \Psi$ due to $\mathrm{Ca}^{2+}$ uptake is not followed by recovery to a hyperpolarized state at any $\mathrm{Ca}^{2+}$ concentration and is associated with a decreased ROS generation. In these effects of $\mathrm{Ca}^{2+}$, clearly the $\Delta \Psi$-dependent feature of ROS generation is reflected.

\section{PERMEABILITY TRANSITION, $\mathrm{Ca}^{2+}$, AND ROS GENERATION}

Several reports demonstrate that the opening of PTP correlates with an increase in ROS production in vitro 


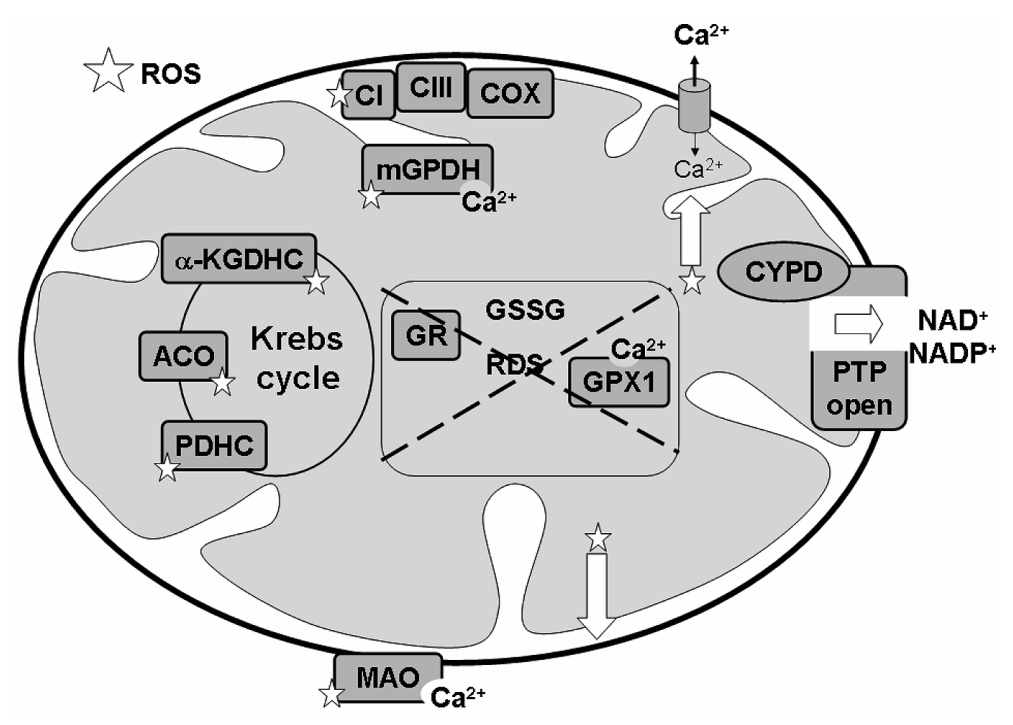

Fig. 2. Enhancement of ROS production in mitochondria that underwent $\mathrm{Ca}^{2+}$-induced permeability transition. Abbreviations are the same as in Fig. 1. Overloading of mitochondria with $\mathrm{Ca}^{2+}$ results in PTP opening, which in turn, results in leakage of pyridine nucleotides $\left(\mathrm{NAD}{ }^{+}\right.$, NADP) and Krebs cycle substrates such as oxaloacetate, alpha-ketoglutarate, and malate from the mitochondrial matrix. This renders both the Krebs cycle and RDS inoperable and results in sever oxidation of mitochondrial glutathione. Leakage of NAD ${ }^{+}$also stimulates ROS production by $\alpha$-KGDHC and PDHC. In addition to that, elevated $\mathrm{Ca}^{2+}$ inhibits GPX1, and directly stimulates ROS production by MAO and mGPDH. Elevated intramitochondrial ROS may further damage aconitase and complex I thereby turning them into ROS sources. Both the inability of permeabilized mitochondria to efficiently scavenge ROS (due to the damage of the RDS) and the elevated primary ROS production contribute to the enhanced ROS emission from mitochondria.

in isolated mitochondria [151,152] and in situ in rat CA1 pyramidal neurons in organotypical slices [153]. However, to the best of our knowledge, no study has yet been published detailing the molecular mechanism of this phenomenon. This is a controversial issue as PTP induction by $\mathrm{Ca}^{2+}$ is not associated with an increased ROS production in other studies. We even have observed a slight decrease in ROS emission from mitochondria experiencing a $\mathrm{Ca}^{2+}$-induced permeability increase of the inner membrane, which is consistent with a net loss of pyridine nucleotides from the matrix of $\mathrm{Ca}^{2+}$-loaded mitochondria exhibiting PTP [47]. Nevertheless, we can make an educated guess about how $\mathrm{Ca}^{2+}$ overloading of mitochondria and/or PTP opening could significantly induce their ROS production (Fig. 2).

As illustrated in Figs 1 and 2, brain mitochondria contain several potential ROS sources such as monoamine oxidase (MAO), complex I, $\alpha$-KGDHC, PDHC, and $\alpha$-glycerophosphate dehydrogenase, and also quite efficient ROS defense system. The latter is "fed" by NADPH that is used by glutathione reductase (GR) to regenerate oxidized glutathione (GSSG) to GSH, which is further used by glutathione peroxidase 1 (GPx1) to detoxify $\mathrm{H}_{2} \mathrm{O}_{2}$ and by thioredoxin reductase that regenerates oxidized thioredoxin, peroxiredoxins, and glutaredoxin. For generation of NADPH in brain mitochondria, malic enzyme and NADP-linked isocitrate dehydrogenase (reviewed in $[55,68]$ ) use the metabolites generated in the Krebs cycle. However, the Krebs cycle cannot operate in permeabilized mitochondria, because its metabolites and perhaps more important, pyridine nucleotides are released from the matrix of mitochondria through the PTP. Indeed, loss of mitochondrial matrix pyridine nucleotides is a prominent consequence of the PTP opening as demonstrated both in vitro in isolated mitochondria and in vivo in perfused rat heart [154]. Moreover, net loss of $\mathrm{NAD}^{+}$was also observed in cell cytosol due likely to the activation of $\mathrm{NAD}^{+}$-glycohydrolase, which is associated primarily with the cytosolic surface of mitochondria [154].

In addition to that, a mitochondrion undergoing PTP opening is de-energized, cannot accumulate $\mathrm{Ca}^{2+}$, and therefore is incapable of controlling the $\mathrm{Ca}^{2+}$ concentration in its vicinity. This would further increase constitutive ROS production because at least two of the mitochondrial ROS sources are stimulated by elevated $\mathrm{Ca}^{2+} ; \alpha$-glycerophosphate dehydrogenase [112] and MAO-A as demonstrated in primary hippocampal cell cultures and in HT-22 cells [155]. 
On the other hand, the constitutive scavenging of ROS is expected to be diminished in permeabilized mitochondria because of the loss of GSH from the matrix space. Although the intramitochondrial GSH pool is about the same as in cytosol, ca. 2-14 mM [80-83] so no dilution would occur, it would no longer be regenerated inside mitochondria due to the loss of NADPH. The net loss of GSH/GSSG was demonstrated in mitochondria isolated from brain subjected to ischemia and reperfusion in vivo [156], a treatment that is firmly associated with the PTP opening. To make things worse, $\mathrm{Ca}^{2+}$ overloading can directly diminish mitochondrial $\mathrm{H}_{2} \mathrm{O}_{2}$ scavenging capacity by inhibiting glutathione reductase/peroxidase system [157].

Summarizing, it seems quite feasible that in vivo, PTP opening could stimulate mitochondrial ROS production both due to a net increase in ROS emission and a failure in ROS scavenging. In line with this conclusion, a recent study by Wang and colleagues [158] has demonstrated that PTP opening in mitochondria in intact cells generates superoxide. This study is remarkable and innovative in many aspects; in particular, it is fascinating that the authors apparently have managed to prove two fundamentally important phenomena, namely the possibility and physiological relevance of spontaneous PTP opening at the level of individual mitochondria in a living cell and the association of PTP opening with a burst of superoxide production. In these experiments, a circularly permuted yellow fluorescent protein (cpYFP) sensitive to superoxide was modified with a mitochondria-targeting sequence and transfected into cultured adult cardiomyocytes, where it localized to mitochondria. The authors observed random spontaneous bursts of cpYFP fluorescence arising from a single or a pair of functionally intact mitochondria. These flashes were observed in a number of cell types including hippocampal neurons and primary cultures of cardiomyocytes isolated from cpYFP transgenic mice. Most remarkable, these flashes were associated with a temporary drop in $\Delta \Psi \mathrm{m}$ and leakage of matrix-entrapped indicator from mitochondria, were inhibited by well-known PTP inhibitors such as cyclosporin A and bongkrekic acid, and were diminished by knockdown of cyclophilin D, a PTP enhancer. Thus, the authors concluded that the observed phenomenon of spontaneous cpYFP fluorescence was in fact, a result of sporadic PTP opening and closure that was associated with bursts in superoxide production [158].

A growing body of evidence indicates that PTP is involved in the pathology of AD. It has been demonstrated that $\mathrm{A} \beta$ peptides exacerbated the PTP inducing effect of $\mathrm{Ca}^{2+}$ in both liver and brain mitochondria; brain mitochondria being more resistant to the potentiation by $\mathrm{A} \beta$ of $\mathrm{Ca}^{2+}$-induced PTP $[159,160]$. It is remarkable that $\mathrm{A} \beta$ has been shown to induce swelling and cytochrome $\mathrm{c}$ release from isolated brain mitochondria sensitive to PTP inhibition by cyclosporine A [161]. It is interesting that in vitro, the PTP induction by $\mathrm{A} \beta_{25-35}$ does not require massive amounts of exogenous $\mathrm{Ca}^{2+}$; the amount present in mitochondria endogenously is sufficient to facilitate $\mathrm{A} \beta_{25-35}$-induced swelling and accumulation of lipid peroxides [162]. More recently, it was found that $\mathrm{A} \beta_{25-35}$ and $\mathrm{A} \beta_{1-42}$ oligomers, but not fibrils, caused massive influx of $\mathrm{Ca}^{2+}$ into cerebellar granular cells and in situ mitochondrial $\mathrm{Ca}^{2+}$ overload resulting in an increased intracellular ROS production, cyclosporine A-inhibitable permeabilization of mitochondria and cytochrome $\mathrm{c}$ release [163]. This is remarkable as soluble oligomers are thought to mostly contribute to the AD pathological changes in the brain [164]. Perhaps, the strongest evidence that in vivo mitochondrial PTP is directly linked to neuronal damage in $\mathrm{AD}$ pathogenesis has been obtained recently by Du et al. [165]. These authors took advantage of mouse genetically ablated of cyclophilin $\mathrm{D}$ (CYPD), a mitochondrial protein that regulates the $\mathrm{Ca}^{2+}$ threshold of PTP opening. CYPD deficient mitochondria open PTP at higher $\mathrm{Ca}^{2+}$ load than wild type mitochondria. [165] have demonstrated that CYPD deficient cortical mitochondria are resistant to $\mathrm{A} \beta$ and $\mathrm{Ca}^{2+}$-induced swelling and PTP opening, exhibit higher $\mathrm{Ca}^{2+}$ buffering capacity, and produce less ROS. The neurons from CYPD knockout mice are also less prone to die when challenged with $\mathrm{A} \beta$ or oxidative stress. Furthermore, CYPD deficiency greatly improves cognitive functions in an AD mouse model/CYPD knockout cross [165].

\section{OTHER FACTORS}

In addition to PTP opening, there are other well documented malfunctions of the mitochondrial machinery caused by over-accumulation of $\mathrm{Ca}^{2+}$ that result in metabolic insufficiency of mitochondria and, therefore, can stimulate mitochondrial ROS production. Inhibition of mitochondrial enzymes, respiration, and oxidative phosphorylation by high $\mathrm{Ca}^{2+}$ is well documented [138,166-168]; among them are several major dehydrogenases of the Krebs cycle, including PDHC [166] and $\alpha$-KGDHC [138]. Accumulated $\mathrm{Ca}^{2+}$ may also decrease the intramitochondrial pool of ADP, thus re- 
ducing the exchangeable pool and the amount of ADP available to the $F_{1}$-ATPase [167]. Accumulation of $\sim 40 \mathrm{nmol} \mathrm{Ca}^{2+}$ by mitochondria strongly inhibited the ATP/ADP translocase activity [148]. Progressive accumulation of large amounts of $\mathrm{Ca}^{2+}$ and $\mathrm{Pi}$ results in $\mathrm{Ca}^{2+}-\mathrm{Pi}$ precipitate formation in the mitochondrial matrix [169,170]; mitochondria from neural tissues can accumulate so much $\mathrm{Ca}^{2+}(2000-4000 \mathrm{nmol} / \mathrm{mg}$ protein [171] that the precipitate may literally fill up the mitochondrial matrix water space, thus creating diffusion limitations for substrate delivery to primary dehydrogenases. All and any of these events are expected to significantly limit the ability of mitochondria to scavenge ROS and/or to increase net mitochondrial ROS emission [55,68].

\section{CONCLUSION}

Convincing evidence is lacking to support the general notion often stated in the literature that $\mathrm{Ca}^{2+}$ accumulation by in situ mitochondria results directly in oxidative stress. There is no known target or mechanism that would uniformly determine the effect of $\mathrm{Ca}^{2+}$ on ROS emission from mitochondria. ROS generation in response to a $\mathrm{Ca}^{2+}$ challenge depends on many variables. In mitochondria not experiencing PTP, the metabolic state is crucial by setting the membrane potential either to a high range of values (no ATP synthesis), where $\mathrm{Ca}^{2+}$ uptake results in a decreased ROS generation, or to a depolarized range (ATP synthesis) in which ROS generation is stimulated or not influenced by $\mathrm{Ca}^{2+}$ depending on the amount of the $\mathrm{Ca}^{2+}$-load. 'Pathological $\mathrm{Ca}^{2+}$ load' covers wide range of $\mathrm{Ca}^{2+}$ concentrations, but effects exerted by $\mathrm{Ca}^{2+}$ in different concentrations within this range are not uniform either. Conditions favoring PTP induction or opposite, delaying $\mathrm{Ca}^{2+}$ induced pore formation are also crucial for alterations in the mitochondrial ROS emission by $\mathrm{Ca}^{2+}$; however, the mechanism underlying the PTP-related changes in ROS release from mitochondria is yet to be elucidated.

Finally, it is important to emphasize that while isolated mitochondria are extremely useful for studies on $\mathrm{Ca}^{2+}$-induced changes in ROS generation allowing to choose the most/least favorable conditions for the dissection of a particular aspect of the $\mathrm{Ca}^{2+}$ action, the extrapolation of results to the in vivo function needs extreme caution since the intracellular environment for in situ mitochondria are far more complex and the respiratory sate is highly dynamic.

\section{ACKNOWLEDGMENTS}

Works by V.A-V cited in this review was supported by OTKA (81983) and Hungarian Academy of Sciences to V.A-V. This work was also supported in part by NIH grants AG014930 and NS065396 to A.A.S.

Authors' disclosures available online (http://www.jalz.com/disclosures/view.php?id=391).

\section{REFERENCES}

[1] Moreira PI, Cardoso SM, Santos MS, Oliveira CR (2006) The key role of mitochondria in Alzheimer's disease. $J$. Alzheimers Dis 9, 101-110.

[2] Moreira PI, Duarte AI, Santos MS, Rego AC, Oliveira CR (2009) An integrative view of the role of oxidative stress, mitochondria and insulin in Alzheimer's disease. J. Alzheimers Dis 16, 741-761.

[3] Nunomura A, Perry G, Aliev G, Hirai K, Takeda A, Balraj $\mathrm{EK}$, Jones $\mathrm{PK}$, Ghanbari $\mathrm{H}$, Wataya $\mathrm{T}$, Shimohama $\mathrm{S}$, Chiba S, Atwood CS, Petersen RB, Smith MA (2001) Oxidative damage is the earliest event in Alzheimer disease. $J$ Neuropathol Exp Neurol 60, 759-767.

[4] Su B, Wang X, Nunomura A, Moreira PI, Lee HG, Perry G, Smith MA, Zhu X (2008) Oxidative stress signaling in Alzheimer's disease. Curr Alzheimer Res 5, 525-532.

[5] Moreira PI, Carvalho C, Zhu XW, Smith MA, Perry G (2010) Mitochondrial dysfunction is a trigger of Alzheimer's disease pathophysiology. Biochim Biophys Acta 1802, 2-10.

[6] Chinopoulos C, Adam-Vizi V (2006) Calcium, mitochondria and oxidative stress in neuronal pathology - Novel aspects of an enduring theme. FEBS $J \mathbf{2 7 3}, 433-450$.

[7] Chtistophe M, Nicolas S (2006) Mitochondria: A target for neuroprotective interventions in cerebral ischemiareperfusion. Curr Pharm Design 12, 739-757.

[8] Droge W, Schipper HM (2007) Oxidative stress and aberrant signaling in aging and cognitive decline. Aging Cell 6, 361370 .

[9] Giordano FJ (2005) Oxygen, oxidative stress, hypoxia, and heart failure. J Clin Invest 115, 500-508.

[10] Orrenius S (2007) Reactive oxygen species in mitochondriamediated cell death. Drug Metab Rev 39, 443-455.

[11] Perez-Pinzon MA, Dave KR, Raval AP (2005) Role of reactive oxygen species and protein kinase $\mathrm{C}$ in ischemic tolerance in the brain. Antioxid Redox Signal 7, 1150-1157.

[12] Siesjo B, Elmer E, Janelidze S, Keep M, Kristian T, Ouyang Y, Uchino H (1999) Role and mechanisms of secondary mitochondrial failure. Acta Neurochir Suppl 73, 7-13.

[13] Starkov AA, Chinopoulos C, Fiskum G (2004) Mitochondrial calcium and oxidative stress as mediators of ischemic brain injury. Cell Calcium 36, 257-264.

[14] Valko M, Leibfritz D, Moncol J, Cronin MTD, Mazur M, Telser J (2007) Free radicals and antioxidants in normal physiological functions and human disease. Int J Biochem Cell Biol 39, 44-84.

[15] Hirai K, Aliev G, Nunomura A, Fujioka H, Russell RL, Atwood CS, Johnson AB, Kress Y, Vinters HV, Tabaton M, Shimohama S, Cash AD, Siedlak SL, Harris PLR, Jones PK, Petersen RB, Perry G, Smith MA (2001) Mitochondrial abnormalities in Alzheimer's disease. J Neurosci 21, 3017-3023. 
[16] Casadesus G, Smith MA, Basu S, Hua J, Capobianco DE, Siedlak SL, Zhu XW, Perry G (2007) Increased isoprostane and prostaglandin are prominent in neurons in Alzheimer disease. Mol Neurodegener 2, 8 .

[17] Honda K, Smith MA, Zhu XW, Baus D, Merrick WC, Tartakoff AM, Hattier T, Harris PL, Siedlak SL, Fujioka H, Liu Q, Moreira PI, Miller FP, Nunomura A, Shimohama S, Perry $\mathrm{G}$ (2005) Ribosomal RNA in Alzheimer disease is oxidized by bound redox-active iron. J Biol Chem 280, 20978-20986.

[18] Pratico D, Uryu K, Leight S, Trojanowswki JQ, Lee VMY (2001) Increased lipid peroxidation precedes amyloid plaque formation in an animal model of Alzheimer amyloidosis. $J$ Neurosci 21, 4183-4187.

[19] Calingasan NY, Chun WJ, Park LCH, Uchida K, Gibson GE (1999) Oxidative stress is associated with region-specific neuronal death during thiamine deficiency. J. Neuropathol Exp Neurol 58, 946-958.

[20] Pappolla MA, Chyan YJ, Omar RA, Hsiao K, Perry G, Smith MA, Bozner P (1998) Evidence of oxidative stress and in vivo neurotoxicity of beta-amyloid in a transgenic mouse model of Alzheimer's disease - A chronic oxidative paradigm for testing antioxidant therapies in vivo. Am J Pathol 152, 871877.

[21] Smith MA, Hirai K, Hsiao K, Pappolla MA, Harris PLR, Siedlak SL, Tabaton M, Perry G (1998) Amyloid-beta deposition in Alzheimer transgenic mice is associated with oxidative stress. J Neurochem 70, 2212-2215.

[22] Matsuoka Y, Picciano M, La Francois J, Duff K (2001) Fibrillar beta-amyloid evokes oxidative damage in a transgenic mouse model of Alzheimer's disease. Neuroscience 104, 609613.

[23] Lustbader JW, Cirilli M, Lin C, Xu HW, Takuma K, Wang N, Caspersen C, Chen X, Pollak S, Chaney M, Trinchese F, Liu SM, Gunn-Moore F, Lue LF, Walker DG, Kuppusamy P, Zewier ZL, Arancio O, Stern D, Yan SSD, Wu H (2004) ABAD directly links A beta to mitochondrial toxicity in Alzheimer's disease. Science 304, 448-452.

[24] Tamagno E, Bardini P, Obbili A, Vitali A, Borghi R, Zaccheo D, Pronzato MA, Danni O, Smith MA, Perry G, Tabaton M (2002) Oxidative stress increases expression and activity of BACE in NT2 neurons. Neurobiol Dis 10, 279-288.

[25] Swerdlow RH, Khan SM (2009) The Alzheimer's disease mitochondrial cascade hypothesis: An update. Exp Neurol 218, 308-315.

[26] Ghanbari HA, Ghanbari K, Harris PLR, Jones PK, Kubat Z, Castellani RJ, Wolozin BL, Smith MA, Perry G (2004) Oxidative damage in cultured human olfactory neurons from Alzheimer's disease patients. Aging Cell 3, 41-44.

[27] Mighore L, Fontana I, Trippi F, Colognato R, Coppede F, Tognoni G, Nucciarone B, Siciliano G (2005) Oxidative DNA damage in peripheral leukocytes of mild cognitive impairment and AD patients. Neurobiol Aging 26, 567-573.

[28] Moreira PI, Harris PLR, Zhu XW, Santos MS, Oliveira CR, Smith MA, Perry G (2007) Lipoic acid and n-acetyl cysteine decrease mitochondrial-related oxidative stress in Alzheimer disease patient fibroblasts. J Alzheimers Dis 12, 195-206.

[29] Perry G, Castellani RJ, Smith MA, Harris PLR, Kubat Z, Ghanbari K, Jones PK, Cordone G, Tabaton M, Wolozin B, Ghanbari H (2003) Oxidative damage in the olfactory system in Alzheimer's disease. Acta Neuropathol 106, 552-556.

[30] Khachaturian ZS (1989) Calcium, membranes, aging, and Alzheimers-disease - introduction overview Ann N Y Acad Sci 568, 1-4.

[31] Cheung KH, Shineman D, Muller M, Cardenas C, Mei LJ
Yang J, Tomita T, Iwatsubo T, Lee VMY, Foskett JK (2008) Mechanism of $\mathrm{Ca} 2+$ disruption in Alzheimer's disease by presenilin regulation of $\operatorname{Ins} \mathrm{P}(3)$ receptor channel gating. Neuron 58, 871-883.

[32] Kuchibhotla KV, Goldman ST, Lattarulo CR, Wu HY, Hyman BT, Bacskai BJ (2008) A beta plaques lead to aberrant regulation of calcium homeostasis in vivo resulting in structural and functional disruption of neuronal networks. Neuron 59, 214-225.

[33] Green KN (2009) Calcium in the initiation, progression and as an effector of Alzheimer's disease pathology. J Cell Mol Med 13, 2787-2799.

[34] Green KN, LaFerla FM (2008) Linking calcium to A beta and Alzheimer's disease. Neuron 59, 190-194.

[35] Bezprozvanny I, Mattson MP (2008) Neuronal calcium mishandling and the pathogenesis of Alzheimer's disease. Trends Neurosci 31, 454-463.

[36] Canevari L, Abramov AY, Duchen MR (2004) Toxicity of amyloid beta peptide: tales of calcium, mitochondria, and oxidative stress. Neurochem Res 29, 637-650.

[37] Mattson MP, Gleichmann M, Cheng A (2008) Mitochondria in neuroplasticity and neurological disorders. Neuron $\mathbf{6 0}$ 748-766.

[38] Duchen MR (2000) Mitochondria and calcium: from cell signalling to cell death. J Physiol Lond 529, 57-68.

[39] Nicholls DG (2009) Mitochondrial calcium function and dysfunction in the central nervous system. Biochim Biophys Acta 1787, 1416-1424.

[40] Rizzuto R, Bernardi P, Pozzan T (2000) Mitochondria as all-round players of the calcium game. J Physiol Lond $\mathbf{5 2 9}$, 37-47.

[41] Das AM, Harris DA (1990) Control of mitochondrial ATP synthase in heart-cells - inactive to active transitions caused by beating or positive inotropic agents. Cardiovasc Res $\mathbf{2 4}$, 411-417.

[42] McCormack JG, Denton RM (1979) Effects of calciumions and adenine-nucleotides on the activity of pig-heart 2oxoglutarate dehydrogenase complex Biochem $J$ 180, 533544.

[43] Mildaziene V, Baniene R, Nauciene Z, Bakker BM, Brown GC, Westerhoff HV, Kholodenko BN (1995) Calcium indirectly increases the control exerted by the adenine nucleotide translocator over 2-oxoglutarate oxidation in rat heart mitochondria. Arch Biochem Biophys 324, 130-134.

[44] Brookes PS, Yoon YS, Robotham JL, Anders MW, Sheu SS (2004) Calcium, ATP, and ROS: a mitochondrial love-hate triangle. Am J Physiol Cell Physiol 287, C817-C833.

[45] Feissner RF, Skalska J, Gaum WE, Sheu SS (2009) Crosstalk signaling between mitochondrial $\mathrm{Ca} 2+$ and ROS. Front Biosci 14, 1197-1218

[46] Gyulkhandanyan AV, Pennefather PS (2004) Shift in the localization of sites of hydrogen peroxide production in brain mitochondria by mitochondrial stress. J Neurochem 90, 405421.

[47] Komary Z, Tretter L, Adam-Vizi V (2008) H2O2 generation is decreased by calcium in isolated brain mitochondria. Biochim Biophys Acta 1777, 800-807.

[48] Starkov AA, Polster BM, Fiskum G (2002) Regulation of hydrogen peroxide production by brain mitochondria by calcium and Bax. J Neurochem 83, 220-228.

[49] Dykens JA (1994) Isolated cerebral and cerebellar mitochondria produce free-radicals when exposed to elevated $\mathrm{Ca} 2+$ and $\mathrm{Na}+$ - implications for neurodegeneration $J$ Neurochem 63, 584-591. 
[50] Hansson MJ, Mansson R, Morota S, Uchino H, Kallur T, Sumi T, Ishii N, Shimazu M, Keep MF, Jegorov A, Elmer E (2008) Calcium-induced generation of reactive oxygen species in brain mitochondria is mediated by permeability transition. Free Radic Biol Med 45, 284-294.

[51] Kowaltowski AJ, Castilho RF, Vercesi AE (1995) Ca2+induced mitochondrial-membrane permeabilization - role of coenzyme-Q redox state. Am J Physiol Cell Physiol 269, C141-C147.

[52] Kowaltowski AJ, Castilho RF, Vercesi AE (1996) Opening of the mitochondrial permeability transition pore by uncoupling or inorganic phosphate in the presence of $\mathrm{Ca} 2+$ is dependent on mitochondrial-generated reactive oxygen species. FEBS Lett 378, 150-152.

[53] Adam-Vizi V (2005) Production of reactive oxygen species in brain mitochondria: Contribution by electron transport chain and non-electron transport chain sources. Antioxid Redox Signal 7, 1140-1149.

[54] Adam-Vizi V, Chinopoulos C (2006) Bioenergetics and the formation of mitochondrial reactive oxygen species. Trends Pharmacol Sci 27, 639-645.

[55] Andreyev AI, Kushnareva YE, Starkov AA (2005) Mitochondrial metabolism of reactive oxygen species. BiochemistryMoscow 70, 200-214.

[56] Boveris A, Chance B (1973) The mitochondrial generation of hydrogen peroxide. General properties and effect of hyperbaric oxygen. Biochem J 134, 707-716.

[57] Chance B, Sies H, Boveris A (1979) Hydroperoxide metabolism in mammalian organs. Physiol Rev 59, 527-605.

[58] Droge W (2002) Free radicals in the physiological control of cell function. Physiol Rev 82, 47-95.

[59] Kowaltowski AJ, de Souza-Pinto NC, Castilho RF, Vercesi AE (2009) Mitochondria and reactive oxygen species. Free Radic Biol Med 47, 333-343.

[60] Murphy M (2008) How mitochondria produce reactive oxygen species. Biochem J 417, 1-13.

[61] Sawyer DT, Valentine JS (1981) How super is superoxide. Acct Chem Res 14, 393-400.

[62] Starkov AA (2006) Protein-mediated energy-dissipating pathways in mitochondria. Chem Biol Interact 163, 133-144.

[63] Turrens JF (2003) Technique monitors oxidative stress. Photonics Spectra 37, 42-42.

[64] Boveris A, Cadenas E, Stoppani AOM (1976) Role of ubiquinone in mitochondrial generation of hydrogenperoxide. Biochem J 156, 435-444.

[65] Cadenas E, Boveris A, Ragan CI, Stoppani AOM (1977) Production of superoxide radicals and hydrogen-peroxide by $\mathrm{NADH}$-ubiquinone reductase and ubiquinol-cytochrome $c$ reductase from beef-heart mitochondria. Arch Biochem Biophys 180, 248-257.

[66] Turrens JF, Alexandre A, Lehninger AL (1985) Ubisemiquinone is the electron-donor for superoxide formation by complex III of heart-mitochondria. Arch Biochem Biophys 237, 408-414.

[67] Turrens JF, Boveris A (1980) Generation of superoxide anion by NADH dehydrogenase of bovine heart-mitochondria. Biochem J 191, 421-427.

[68] Starkov AA (2008) The role of mitochondria in reactive oxygen species metabolism and signaling. In Mitochondria and Oxidative Stress in Neurodegenerative Disorders, Gibson GE, Ratan RR, Beal MF, eds. Blackwell Publishing, Oxford, pp. 37-52.

[69] Starkov AA, Fiskum G, Chinopoulos C, Lorenzo BJ, Browne SE, Patel MS, Beal MF (2004) Mitochondrial alpha-ketoglutarate dehydrogenase complex generates reactive oxygen species. J Neurosci $\mathbf{2 4}$, 7779-7788.

[70] Tretter L, Adam-Vizi V (2004) Generation of reactive oxygen species in the reaction catalyzed by alpha-ketoglutarate dehydrogenase. J Neurosci 24, 7771-7778.

[71] Cino M, Delmaestro RF (1989) Generation of hydrogenperoxide by brain mitochondria - the effect of reoxygenation following postdecapitative ischemia. Arch Biochem Biophys 269, 623-638.

[72] Herrero A, Barja G (2000) Localization of the site of oxygen radical generation inside the complex I of heart and nonsynaptic brain mammalian mitochondria. J Bioenerg Biomemb 32, 609-615.

[73] Starkov AA, Fiskum G (2001) Myxothiazol induces $\mathrm{H} 2 \mathrm{O} 2$ production from mitochondrial respiratory chain. Biochem Biophys Res Commun 281, 645-650.

[74] Votyakova TV, Reynolds IJ (2001) Delta psi(m)-dependent and -independent production of reactive oxygen species by rat brain mitochondria. J Neurochem 79, 266-277.

[75] Zoccarato F, Cavallini L, Deana R, Alexandre A (1988) Pathways of hydrogen-peroxide generation in guinea-pig cerebral-cortex mitochondria. Biochem Biophys Res Comтип 154, 727-734.

[76] Sipos I, Tretter L, Adam-Vizi V (2003) Quantitative relationship between inhibition of respiratory complexes and formation of reactive oxygen species in isolated nerve terminals. $J$ Neurochemy 84, 112-118.

[77] Vogel R, Wiesinger H, Hamprecht B, Dringen R (1999) The regeneration of reduced glutathione in rat forebrain mitochondria identifies metabolic pathways providing the NADPH required. Neurosci Lett 275, 97-100.

[78] Tischler ME, Hecht P, Williamson JR (1977) Effect of ammonia on mitochondrial and cytosolic NADH and NADPH systems in isolated rat-liver cells. FEBS Lett 76, 99-104.

[79] Williamson J, Corkey B (1979) Assay of citric acid cycle intermediates and related compounds - update with tissue metabolite levels and intracellular distribution. Methods Enzymol 55, 200-222.

[80] Griffith OW, Meister A (1985) Origin and turnover of mitochondrial glutathione. Proc Natl Acad Sci U S A 82, 46684672.

[81] Rebrin I, Kamzalov S, Sohal RS (2003) Effects of age and caloric restriction on glutathione redox state in mice. Free Radic Biol Med 35, 626-635.

[82] Rebrin I, Sohal RS (2004) Comparison of thiol redox state of mitochondria and homogenates of various tissues between two strains of mice with different longevities. Exp Gerontol 39, 1513-1519.

[83] Wahllander A, Soboll S, Sies H, Linke I, Muller M (1979) Hepatic mitochondrial and cytosolic glutathione content and the subcellular-distribution of GSH-S-transferases. FEBS Lett 97, 138-140.

[84] Kirichok Y, Krapivinsky G, Clapham DE (2004) The mitochondrial calcium uniporter is a highly selective ion channel. Nature 427, 360-364.

[85] Buntinas L, Gunter KK, Sparagna GC, Gunter TE (2001) The rapid mode of calcium uptake into heart mitochondria (RaM): comparison to RaM in liver mitochondria. Biochim Biophys Acta 1504, 248-261.

[86] Sparagna GC, Gunter KK, Shen SS, Gunter TE (1995) Mitochondrial calcium-uptake from physiological-type pulses of calcium - a description of the rapid uptake mode $J$ Biol Chem 270, 27510-27515.

[87] Beutner G, Sharma VK, Lin L, Ryu SY, Dirksen RT, Sheu 
SS (2005) Type 1 ryanodine receptor in cardiac mitochondria: Transducer of excitation-metabolism coupling. Biochim Biophys Acta 1717, 1-10.

[88] Gunter TE, Buntinas L, Sparagna G, Eliseev R, Gunter K (2000) Mitochondrial calcium transport: mechanisms and functions. Cell Calcium 28, 285-296.

[89] Bernardi P (1999) Mitochondrial transport of cations: Channels, exchangers, and permeability transition. Physiol Rev 79, 1127-1155.

[90] Bernardi P, Krauskopf A, Basso E, Petronilli V, BlalchyDyson E, Di Lisa F, Forte MA (2006) The mitochondrial permeability transition from in vitro artifact to disease target. FEBS J 273, 2077-2099.

[91] Crompton M (1999) The mitochondrial permeability transition pore and its role in cell death. Biochem J 341, 233-249.

[92] Halestrap AP, Kerr PM, Javadov S, Woodfield KY (1998) Elucidating the molecular mechanism of the permeability transition pore and its role in reperfusion injury of the heart. Biochim Biophys Acta 1366, 79-94.

[93] Castilho RF, Kowaltowski AJ, Meinicke AR, Bechara EJH, Vercesi AE (1995) Permeabilization of the inner mitochondrial-membrane by $\mathrm{Ca} 2+$ ions is stimulated by $\mathrm{T}-$ butyl hydroperoxide and mediated by reactive oxygen species generated by mitochondria. Free Radic Biol Med 18, 479486.

[94] Irigoin F, Inada NM, Fernandes MP, Piacenza L, Gadelha FR, Vercesi AE, Radi R (2009) Mitochondrial calcium overload triggers complement-dependent superoxide-mediated programmed cell death in Trypanosoma cruzi. Biochem $J$ 418, 595-604.

[95] Panov A, Dikalov S, Shalbuyeva N, Hemendinger R, Greenamyre JT, Rosenfeld J (2007) Species- and tissuespecific relationships between mitochondrial permeability transition and generation of ROS in brain and liver mitochondria of rats and mice. Am J Physiol Cell Physiol 292, C708-C718.

[96] Schonfeld P, Reiser G (2007) Ca2+ storage capacity of rat brain mitochondria declines during the postnatal development without change in ROS production capacity. Antioxid Redox Signal 9, 191-199.

[97] Votyakova TV, Reynolds IJ (2005) Ca2+-induced permeabilization promotes free radical release from rat brain mitochondria with partially inhibited complex I. J Neurochem 93, 526-537.

[98] Kussmaul L, Hirst J (2006) The mechanism of superoxide production by NADH: ubiquinone oxidoreductase (complex I) from bovine heart mitochondria. Proc Natl Acad Sci US A 103, 7607-7612.

[99] Kudin AP, Bimpong-Buta NYB, Vielhaber S, Elger CE, Kunz WS (2004) Characterization of superoxide-producing sites in isolated brain mitochondria. J Biol Chem 279, 4127-4135.

[100] Kushnareva Y, Murphy AN, Andreyev A (2002) Complex I-mediated reactive oxygen species generation: modulation by cytochrome c and $\mathrm{NAD}(\mathrm{P})(+)$ oxidation-reduction state. Biochem J 368, 545-553.

[101] Chance B, Hollunger G (1961) The interaction of energy and electron transfer reactions in mitochondria. I. General properties and nature of the products of succinate-linked reduction of pyridine nucleotide. J Biol Chem 236, 1534-1543.

[102] Hinkle P, Butow R, Racker E, Chance B (1967) Partial resolution of the enzymes catalyzing oxidative phosphorylation. $\mathrm{XV}$. Reverse electron transfer in the flavin-cytochrome beta region of the respiratory chain of beef heart submitochondrial particles. J Biol Chem 242, 5169-5173.
[103] Liu YB, Fiskum G, Schubert D (2002) Generation of reactive oxygen species by the mitochondrial electron transport chain. J Neurochem 80, 780-787.

[104] Zoccarato F, Cavallini L, Bortolami S, Alexandre A (2007) Succinate modulation of $\mathrm{H} 2 \mathrm{O} 2$ release at $\mathrm{NADH}$ : ubiquinone oxidoreductase (Complex I) in brain mitochondria. Biochem J 406, 125-129.

[105] Benzi G, Arrigoni E, Marzatico F, Villa RF (1979) Influence of some biological pyrimidines on the succinate cycle during and after cerebral-ischemia Biochem Pharmacol 28, 25452550.

106] Folbergrova J, Ljunggren B, Norberg K, Siesjo B (1974) Influence of complete ischemia on glycolytic metabolites, citric acid cycle intermediates, and associated amino acids in the rat cerebral cortex. Brain Res 80, 265-279.

[107] Khazanov VA, Poborsky AN, Kondrashova MN (1992) Air saturation of the medium reduces the rate of phosphorylating oxidation of succinate in isolated-mitochondria. FEBS Lett 314, 264-266.

[108] Poborskii A (1997) Effect of research conditions on succinate oxidation in brain mitochondria in circulatory hypoxia. Patol Fiziol Eksp Ter 1, 10-12.

[109] Korshunov SS, Skulachev VP, Starkov AA (1997) High protonic potential actuates a mechanism of production of reactive oxygen species in mitochondria. FEBS Lett 416, 15-18.

[110] Tretter L, Takacs K, Hegedus V, Adam-Vizi V (2007) Characteristics of alpha-glycerophosphate-evoked $\mathrm{H} 2 \mathrm{O} 2$ generation in brain mitochondria. $J$ Neurochem 100, 650-663.

[111] Miwa S, Brand MD (2005) The topology of superoxide production by complex III and glycerol 3-phosphate dehydrogenase in Drosophila mitochondria. Biochim Biophys Acta 1709, 214-219.

112] Tretter L, Takacs K, Kover K, Adam-Vizi V (2007) Stimulation of $\mathrm{H} 2 \mathrm{O} 2$ generation by calcium in brain mitochondria respiring on alpha-glycerophosphate. J Neurosci Res $\mathbf{8 5}$, 3471-3479.

[113] Wernette ME, Ochs RS, Lardy HA (1981) Ca2+ stimulation of rat-liver mitochondrial glycerophosphate dehydrogenase. J Biol Chem 256, 2767-2771.

[114] Butterworth RF, Besnard AM (1990) Thiamine-dependent enzyme changes in temporal cortex of patients with alzheimers-disease. Metab Brain Dis 5, 179-184.

[115] Gibson GE, Starkov A, Blass JP, Ratan RR, Beal MF (1988) Cause and consequence: Mitochondrial dysfunction initiates and propagates neuronal dysfunction, neuronal death and behavioral abnormalities in age-associated neurodegenerative diseases. Biochim Biophys Acta 1802, 122-134.

[116] Mastrogiacomo F, Lindsay JG, Bettendorff L, Rice J, Kish SJ (1996) Brain protein and alpha-ketoglutarate dehydrogenase complex activity in Alzheimer's disease. Ann Neurol 39, 592 598.

[117] Gibson GE, Starkov A, Blass JP, Ratan RR, Beal MF (2010) Cause and consequence: Mitochondrial dysfunction initiates and propagates neuronal dysfunction, neuronal death and behavioral abnormalities in age-associated neurodegenerative diseases. Biochim Biophys Acta 1802, 122-134.

[118] Caspersen C, Wang N, Yao J, Sosunov A, Chen X, Lustbader JW, Xu HW, Stern D, McKhann G, Yan SD (2005) Mitochondrial A beta: a potential focal point for neuronal metabolic dysfunction in Alzheimer's disease. FASEB $J \mathbf{1 9}$, 2040-2041.

[119] Casley CS, Canevari L, Land JM, Clark JB, Sharpe MA (2002) Beta-amyloid inhibits integrated mitochondrial respiration and key enzyme activities. J Neurochem 80, 91-100. 
[120] Kumar MJ, Nicholls DG, Andersen JK (2003) Oxidative alpha-ketoglutarate dehydrogenase inhibition via subtle elevations in monoamine oxidase $\mathrm{B}$ levels results in loss of spare respiratory capacity - Implications for Parkinson's disease. J Biol Chem 278, 46432-46439.

[121] Nulton-Persson AC, Szweda LI (2001) Modulation of mitochondrial function by hydrogen peroxide. J Biol Chem 276, 23357-23361.

[122] Tretter L, Adam-Vizi V (2000) Inhibition of Krebs cycle enzymes by hydrogen peroxide: A key role of alphaketoglutarate dehydrogenase in limiting NADH production under oxidative stress. J Neurosci 20, 8972-8979.

[123] Park LCH, Zhang H, Sheu KFR, Calingasan NY, Kristal BS, Lindsay JG, Gibson GE (1999) Metabolic impairment induces oxidative stress, compromises inflammatory responses, and inactivates a key mitochondrial enzyme in microglia. J Neurochem 72, 1948-1958.

[124] Bunik VI, Sievers C (2002) Inactivation of the 2-oxo acid dehydrogenase complexes upon generation of intrinsic radical species. Eur J Biochem 269, 5004-5015.

[125] Tahara EB, Navarete FDT, Kowaltowski AJ (2009) Tissue-, substrate-, and site-specific characteristics of mitochondrial reactive oxygen species generation. Free Radic Biol Med 46, 1283-1297.

[126] Tretter L, Adam-Vizi V (2005) Alpha-ketoglutarate dehydrogenase: a target and generator of oxidative stress. Philos $T$ Roy Soc B 360, 2335-2345.

[127] Carothers DJ, Pons G, Patel MS (1989) Dihydrolipoamide dehydrogenase - functional similarities and divergent evolution of the pyridine nucleotide-disulfide oxidoreductase Arch Biochem Biophys 268, 409-425.

[128] Panov A, Scarpa A (1996) Independent modulation of the activity of alpha-ketoglutarate dehydrogenase complex by $\mathrm{Ca} 2+$ and Mg2+. Biochem 35, 427-432.

[129] Zundorf G, Kahlert S, Bunik VI, Reiser G (2009) Alphaketoglutarate dehydrogenase contributes to production of reactive oxygen species in glutamate-stimulated hippocampal neurons in situ. Neuroscience 158, 610-616.

[130] Budd SL, Nicholls DG (1996) Mitochondria, calcium regulation, and acute glutamate excitotoxicity in cultured cerebellar granule cells. J Neurochem 67, 2282-2291.

[131] Chinopoulos C, Gerencser AA, Doczi J, Fiskum G, AdamVizi V (2004) Inhibition of glutamate-induced delayed calcium deregulation by 2 -APB and $\mathrm{La} 3+$ in cultured cortical neurones. J Neurochem 91, 471-483.

[132] Dugan LL, Sensi SL, Canzoniero LMT, Handran SD, Rothman SM, Lin TS, Goldberg MP, Choi DW (1995) Mitochondrial production of reactive oxygen species in corticalneurons following exposure to N-Methyl-D-Aspartate. $J$ Neurosci 15, 6377-6388.

[133] Lafoncazal M, Pietri S, Culcasi M, Bockaert J (1993) NMDA-dependent superoxide production and neurotoxicity. Nature 364, 535-537.

[134] Nieminen AL, Petrie TG, Lemasters JJ, Selman WR (1996) Cyclosporin a delays mitochondrial depolarization induced by N-methyl-D-aspaparte in cortical neurons: Evidence of the mitochondrial permeability transition. Neuroscience $\mathbf{7 5}$, 993-997.

[135] Patel M, Day BJ, Crapo JD, Fridovich I, McNamara JO (1996) Requirement for superoxide in excitotoxic cell death. Neuron 16, 345-355.

[136] Reynolds IJ, Hastings TG (1995) Glutamate induces the production of reactive oxygen species in cultured forebrain neurons following NMDA receptor activation. J Neurosci 15,
3318-3327.

[137] White RJ, Reynolds IJ (1996) Mitochondrial depolarization in glutamate-stimulated neurons: An early signal specific to excitotoxin exposure. J Neurosci 16, 5688-5697.

[138] Lai J, Cooper A (1986) Brain alpha-ketoglutarate dehydrogenase complex: kinetic properties, regional distribution, and effects of inhibitors. J Neurochem 47, 1376-1386.

[139] Hansford RG, Hogue BA, Mildaziene V (1997) Dependence of $\mathrm{H} 2 \mathrm{O} 2$ formation by rat heart mitochondria on substrate availability and donor age. J Bioenerg Biomemb 29, 89-95.

[140] Tretter L, Mayer-Takacs D, Adam-Vizi V (2007) The effect of bovine serum albumin on the membrane potential and reactive oxygen species generation in succinate-supported isolated brain mitochondria. Neurochem Int 50, 139-147.

[141] Starkov AA, Fiskum G (2003) Regulation of brain mitochondrial $\mathrm{H} 2 \mathrm{O} 2$ production by membrane potential and $\mathrm{NAD}(\mathrm{P}) \mathrm{H}$ redox state. J Neurochem 86, 1101-1107.

[142] Tretter L, Adam-Vizi V (2007) Moderate dependence of ROS formation on Delta psi $\mathrm{m}$ in isolated brain mitochondria supported by NADH-linked substrates. Neurochem Res 32, 569575.

[143] Komary Z, Tretter L, Adam-Vizi V (2010) Membrane potential-related effect of calcium on reactive oxygen species generation in isolated brain mitochondria. Biochim Biophys Acta, in press.

[144] Brustovetsky N, Dubinsky JM (2000) Limitations of cyclosporin A inhibition of the permeability transition in CNS mitochondria. J Neurosci 20, 8229-8237.

[145] Crompton M, Costi A (1988) Kinetic evidence for a heart mitochondrial pore activated by $\mathrm{Ca} 2+$, inorganic-phosphate and oxidative stress - a potential mechanism fot mitochondrial dysfunction during cellular Ca2+ overload. Eur J Biochem 178, 489-501.

[146] Halestrap AP, Davidson AM (1990) Inhibition of Ca2+induced large-amplitude swelling of liver and heartmitochondria by cyclosporine is probably caused by the inhibitor binding to mitochondrial-matrix peptidyl-prolyl cis-trans isomerase and preventing it interacting with the adenine-nucleotide translocase. Biochem J 268, 153-160.

[147] Hunter DR, Haworth RA (1979) Ca2+-induced membrane transition in mitochondria. 1. protective mechanisms. Arch Biochem Biophys 195, 453-459.

[148] Gomezpuyou A, Tuenadegomezpuyou M, Klapp M, Carafoli E (1979) Effect of calcium on the translocation of adeninenucleotides in rat-liver mitochondria. Arch Biochem Biophys 194, 399-404.

[149] Bogucka K, Teplova VV, Wojtczaka L, Evtodienko YV (1995) Inhibition by $\mathrm{Ca} 2+$ of the hydrolysis and the synthesis of ATP in ehrlich ascites tumor mitochondria - relation to the crabtree effect. Biochim Biophys Acta 1228, 261-266.

[150] Tuenadegomezpuyou M, Gavilanes M, Gomezpuyou A, Ernster L (1980) Control of activity states of heart mitochondrial ATPase role of the proton-motive force and $\mathrm{Ca} 2+$. Biochim Biophys Acta 592, 396-405.

[151] Kowaltowski AJ, Naia-da-Silva ES, Castilho RF, Vercesi $\mathrm{AE}$ (1998) Ca2+-stimulated mitochondrial reactive oxygen species generation and permeability transition are inhibited by dibucaine or Mg2+. Arch Biochem Biophys 359, 77-81.

[152] Maciel EN, Vercesi AE, Castilho RF (2001) Oxidative stress in $\mathrm{Ca} 2+$-induced membrane permeability transition in brain mitochondria. J Neurochem 79, 1237-1245.

[153] Frantseva MV, Carlen PL, Velazquez JLP (2001) Dynamics of intracellular calcium and free radical production during ischemia in pyramidal neurons. Free Radic Biol Med 
31, 1216-1227.

[154] Di Lisa F, Menabo R, Canton M, Barile M, Bernardi P (2001) Opening of the mitochondrial permeability transition pore causes depletion of mitochondrial and cytosolic $\mathrm{NAD}(+)$ and is a causative event in the death of myocytes in postischemic reperfusion of the heart. $J$ Biol Chem 276, 2571-2575.

[155] Cao X, Wei ZL, Gabriel GG, Li XM, Mousseau DD (2007) Calcium-sensitive regulation of monoamine oxidase-A contributes to the production of peroxyradicals in hippocampal cultures: implications for Alzheimer disease-related pathology. BMC Neurosci 8, 10 .

[156] Anderson MF, Sims NR (2002) The effects of focal ischemia and reperfusion on the glutathione content of mitochondria from rat brain subregions. J Neurochem 81, 541-549.

[157] Zoccarato F, Cavallini L, Alexandre A (2004) Respirationdependent removal of exogenous $\mathrm{H} 2 \mathrm{O} 2$ in brain mitochondria - Inhibition by Ca2+. J Biol Chem 279, 4166-4174.

[158] Wang W, Fang H, Groom L, Cheng A, Zhang W, Liu J, Wang X, Li K, Han P, Zheng M, Yin J, Mattson MP, Kao JP, Lakatta EG, Sheu SS, Ouyang K, Chen J, Dirksen RT, Cheng H (2008) Superoxide flashes in single mitochondria. Cell 134, 279-290.

[159] Moreira PI, Santos MS, Moreno A, Oliveira C (2001) Amyloid beta-peptide promotes permeability transition pore in brain mitochondria. Biosci Rep 21, 789-800.

[160] Moreira PI, Santos MS, Moreno A, Rego AC, Oliveira C (2002) Effect of amyloid beta-peptide on permeability transition pore: A comparative study. J Neurosci Res 69, 257-267.

[161] Kim HS, Lee JH, Lee JP, Kim EM, Chang KA, Park CH, Jeong SJ, Wittendorp MC, Seo JH, Choi SH, Suh YH (2002) Amyloid beta peptide induces cytochrome c release from isolated mitochondria. Neuroreport 13, 1989-1993.

[162] Shevtzova EF, Kireeva EG, Bachurin SO (2001) Effect of beta-amyloid peptide fragment 25-35 on nonselective perme- ability of mitochondria. Bull Exp Biol Med 132, 1173-1176.

[163] Sanz-Blasco S, Valero RA, Rodriguez-Crespo I, Villalobos C, Nunez L (2008) Mitochondrial Ca2+ overload underlies a beta oligomers neurotoxicity providing an unexpected mechanism of neuroprotection by NSAIDs. PLOS ONE 3, 16.

[164] Haass C, Selkoe DJ (2007) Soluble protein oligomers in neurodegeneration: lessons from the Alzheimer's amyloid beta-peptide. Nat Rev Mol Cell Biol 8, 101-112.

[165] Du H, Guo L, Fang F, Chen D, Sosunov AA, McKhann GM, Yan YL, Wang CY, Zhang H, Molkentin JD, Gunn-Moore FJ, Vonsattel JP, Arancio O, Chen JX, Du Yan S (2008) Cyclophilin D deficiency attenuates mitochondrial and neuronal perturbation and ameliorates learning and memory in Alzheimer's disease. Nat Med 14, 1097-1105.

[166] Lai JCK, Dilorenzo JC, Sheu KFR (1988) Pyruvatedehydrogenase complex is inhibited in calcium-loaded cerebrocortical mitochondria. Neurochem Res 13, 1043-1048.

[167] Roman I, Clark A, Swanson PD (1981) The interaction of calcium-transport and ADP phosphorylation in brain mitochondria. Membrane Biochem 4, 1-9.

[168] Villalobo A, Lehninger AL (1980) Inhibition of oxidativephosphorylation in ascites tumor mitochondria and cells by intra-mitochondrial Ca2+. J Biol Chem 255, 2457-2464.

[169] Chalmers S, Nicholls DG (2003) The relationship between free and total calcium concentrations in the matrix of liver and brain mitochondria. J Biol Chem 278, 19062-19070.

[170] Kristian T, Weatherby TM, Bates TE, Fiskum G (2002) Heterogeneity of the calcium-induced permeability transition in isolated non-synaptic brain mitochondria. J Neurochem $\mathbf{8 3}$, 1297-1308.

[171] Chinopoulos C, Starkov AA, Fiskum G (2003) Cyclosporin A-insensitive permeability transition in brain mitochondria Inhibition by 2 -aminoethoxydiphenyl borate. $\mathrm{J}$ Biol Chem 278, 27382-27389. 